\title{
PERFORMANCE BASED PROFESSIONAL DEVELOPMENT OF IN-SERVICE TEACHERS
}

\author{
Sidra Rizwan \\ Lecturer, \\ Department of Secondary Teacher Education, AIOU, \\ Islamabad, Pakistan \\ Email: sidra.rizwan@ aiou.edu.pk
}

\begin{abstract}
Developing countries all over the world are struggling to improve their education system to achieve sustainable development standards. Pakistan being a developing country is no different; the two major issues related to education are quality and quantity and both are imperative in our current situation where we are up against the challenges of low literacy and poor quality of education. The government has taken up the challenge of low quality of education by investing in teacher education in the form of various reforms which are designed to enhance the teaching quality and provide standards of acceptability across the country. In this regard professional standards in 2009 were launched across the country for teachers. The latest concept of teaching is no more transfer of knowledge rather it is the transformation of knowledge in an organized manner. This organized knowledge transformation requires detailed planning and multiple strategies of delivery; this concept took the fourth place in the professional standards as "Instructional Planning and Strategies". This standard has three dimensions one of which is "Performance" with eight indicators that can be used to measure this dimension. This article focuses on the performance of in-service teachers teaching at secondary level gauged on the defined indicators of performance in instructional planning \& strategies stated in the professional standards. The population was teachers already teaching at secondary level from all the four provinces and Islamabad, according to multistage sampling technique 400 teachers were selected and further their 80 head teachers were also included for the purpose of triangulation. The findings showed that currently in-service teachers required training at varying degree on all the indicators of performance which provided the basis for priority wise training recommendations according to the defined indicators. The challenge of quality teaching in the country can be addressed if the teachers perform according to the prescribed standards.
\end{abstract}

\section{KEYWORDS}

Instructional planning, in service teachers, Professional standards for teachers, Performance indicators, National standards 


\section{INTRODUCTION}

Teachers are the foundation of any educational system and considered as nation builders. The teaching profession demands dedication, refinement of pedagogical skills, and pursuit of continuous professional development. Brookfield, 2006 suggests rigorous efforts not only in equipping teachers with pedagogical competencies but also to inculcate positive mind-set in them, which ignites the urge for continuous learning and development for teaching at any level for professionals who are passionate, competent, and well trained.

The teaching standards are defined in national standards for teachers to ensure and maintain teaching quality which will help produce globally competent teachers who are responsible for the future generations. These standards determine the precise expectations from the teachers in the three dimensions related to knowledge, attitude, and performance aspects of each standard.

It is an admitted fact that quality teachers are indispensable for quality education, as the learners rely on their teachers for guidance, knowledge, and motivation for learning purposes. Those professionals whose belief is strong over the stated fact consider professional development as a ladder towards learning process. To combat with the global challenges, Pakistan requires enhancing quality of teacher education agreeing with the international standards. The first and the foremost duty of the government is to be responsible for quality education for all.

The standards for the competent teachers' production are fixed based on teachers' knowledge and abilities of performance. Generally, the factors of specific expectations are related by standards. Standards confirm the level of knowledge, proficiencies and abilities of the teachers who endorse student learning. It is true that the content of the standard is significant but the way the standard is measured to confirm whether the specific standard is met or not, cannot be ignored.

The issue of education in the public sector of Pakistan is well debated. The provision of quality education to all the citizens is the primary duty of the government. Our government is also dedicated to this, different progressive measure is being initiated in this regard for the training and development of teachers nationwide. The good governance of Pakistan is very much responsible in this regard and is taking solid measures to enhance the vision of teacher training and education programs throughout the country. In the last two decades, the government has taken substantial measures generally to improve the system of education and particularly enhancing the quality of teacher education. It is concrete consideration of Pakistani government's concerns about future of education. If Pakistan aspire to contest efficiently in the knowledge at global level and transform the raw asset into dynamic talent, it must produce a prolific 
system of education from primary to postgraduate level.

According to National Education Policy 2009, quality education is determined by teacher education because how the teachers teach in the class is directly related to the learning of the children and these two combines to translate quality education. Teachers' training quality must be exceptional to meet the product of outstanding teachers. Without efficient teachers, an effective system of education is not possible. Those teachers who are professional in their approach and keep on developing their competencies continuously, play a pivotal role in quality education.

The professional literature clearly identifies the basic needs in production of world class teachers and to equip them with the skills required for education of generations of scholars. The literature includes the standards what the teacher is required to know and what is he capable to do.

The teachers and other educators' professional development based on standards is a part of quality assurance movement at international level in various fields of human struggle. In the field of education, quality education critically analyzes the factors responsible for quality education, observes their occurrence within the system and evaluates the effects on learning outcomes of students.

To improve teaching quality in the year 2009 the government pioneered professional standards for teachers for primary level novice teachers, but they could be tailored and used by teachers teaching at secondary level too. These standards were launched after the provincial and federal acknowledgement which specified the domains of defined professional outcomes regarding knowledge, attitude, and performance of teachers. Since the introduction of National Professional Standards for teachers many interventions have been made to improve teacher preparation programs which are intended to improve teaching quality. Yet the reports do not clarify the extent of improvement or impact of these interventions.

The data of National Education Census (NEC) 2005 and a large number of studies show that professional training of teachers in Pakistan is neither standardized nor based on adequate professional standards. Traditionally, teacher education has been regarded as a subject at provincial level. Each province has its own distinctive centralized administrative structure that prepares the teachers at every level: primary, middle, and secondary school.

The Universities, Colleges, Departments of Education, IERs and the newly developed Universities of Education are responsible for the Bachelor and Postgraduate level programs. There were only 257,818 B.Ed degree holder teachers and 67,143 M.Ed 
degree holder teachers as per NEC data in 2005. Most of the teachers with B.Ed or M.Ed degree had completed their Bachelor or Master degree as well. After twelve year of education, a two-year education program has been called bachelor's degree in 2005.

There is a centralized system of administration of Teacher Professional Development (TPD) in each province. In Pakistan, there are 270 TPD institutions at present. The Provincial Department of Education operates 227 institutions as public sector whereas the rest are in Private sector control. Neither the programs nor the TPD institutions have been exposed to any grave inspection basing the evident and impartial standard or any criteria of accreditation.

The present dynamics of education redefines teaching as transformation of knowledge which is well planned and organized rather than mere transfer of knowledge. Here the planning and organization of teaching is of immense importance which can be made successful through immaculate instructional planning and diverse strategies what may target the diversified audience in contemporary classrooms. This highlighted the concept of "Instructional Planning \& Strategies" as an established professional national standard for teachers.

Performance is one of the dimensions of this standard which is based upon teachers' abilities of utilization of multiple strategies with respect to the age of students primarily for developing skills pertaining to problem solving and critical thinking. It is sub categorized into eight indicators which provide the basis for independent measurement of this dimension. Some mandatory classroom teaching skills are required of the teacher for the promotion of learning and discipline. Teaching cannot be effective unless it proceeds in a precise way, and such teaching has a pronounced effect on the holistic process of teaching and learning. Ehindero \& Ajibade (2000) envisioned teaching as a process of appreciating the emerging trends and procedures in teaching learning domain along with on-going professional development and individual growth.

Rice (2010) concluded that experience has importance, 'but more is not always better.' He concluded that in the initial years teaching experience impacts the teaching of the individuals more and as the experience accumulates its effect starts diminishing.

Further findings of many related research confirm that novice teachers are less effective than experienced ones (Clotfelter, Ladd, and Vigdor2007). Experience of initial years surely adds to the effectiveness of a teacher and it has lasting impression than most of the other teacher-related observable variables i.e., licensing of teachers, advanced degrees, score on tests, class size and Elementary Board certification (Clotfelter et al. 2007). Teachers are more creative and productive in the initial years of their career and gradually their performance starts to deteriorate. Boyd, Lankford, 
Loeb, Jonah, Rockoff, \& James (2007) illustrated by utilizing the data of New York City that the diminishing marginal returns are associated with experience.

Amirali \& Halai (2010) concluded that the NPSTP-2009 is perceived highly positive by a great majority of public sector secondary school teachers. The development of these standards was greatly appreciated by the teachers and principal and they perceived them as a mechanism to enhance professional competency and merit. According to gender the male teachers favoured the concept of teaching based on standards than their female counterparts. Location wise urban teachers were more receptive of NPST-2009 than the rural teachers. This scenario demanded increased professional training of rural teachers. A variety of variables i.e., age, experience, grade and designation, academic and professional qualification posed no difference.

According to Shakir \& Adeeb (2014) the male SSTs showed greater competence levels than the female teachers. They were more dominating and authoritative as compared to the female teachers for that reason their classrooms demonstrated discipline, organization, and control. Regarding location the teachers working in urban settings performed better than those living in rural settings.

Many researches show that professional development involving many factors contributed to the performance of the of in-service teachers (Kutaka, Smith, Albano, Edwards, Ren,,\& Beattie, 2017). Professional development is conducted through teacher training programs which increase teachers' knowledge and skill. (Lampert, Ball, Garcia-Carrion, \& Burnett, 2019) suggested that there are five key structures which make teachers professional development effective: (a) focus on subject matter or the content being delivered to make the performance more result oriented (b) active opportunities like to observe the students in the classroom, get feedback, evaluate students' work, presentations in the classroom and find out the alternatives to lecturing (c) coherence in content presented in the classroom, consistent goals, and activities which suit to goals and school curriculum, teacher belief and knowledge that fulfill the needs of the students (d) teachers' professional development activities may be conducted after continuous period of time and (e)and make collective participation of the teachers in those activities for the maximum outcome which include teachers from all age groups and subjects to build interactive teaching- learning environment in the school.

According to YurtsevenAvci, O'Dwyer, \& Lawson (2020) there are many factors like self-efficacy which may affect the performance of the teachers and professional development of the teachers improve their self-efficacy. Teachers' self-efficacy is the driving force behind the teacher motivation to enhance innovative knowledge and create new dimensions to facilitate the teaching- learning process in the classroom at 
secondary school level (Gutierrez-Cobo, Cabello, Rodiguez-Corrales, Megias-Robles, Gomez-Leal, \& Fernandez-Berrocal, 2019).For effective teachers' professional development skills, believes and motivational factors enhance teacher's ability to use practices and interactive approach to show effective results in the classroom. Going through mutual efficacy, creating positive interactive dependency is the approach based on collective inquiry tends to self-efficacy which leads to effectiveness. Chatelier and Rudolph, (2018) revealed that this method creates prospects for teachers to get involved in construction of educational knowledge together by using conferencing and mutual understating by following four steps: firstly, recognizing the problem, secondly by gathering indications, thirdly, investigating those indications and fourthly, the results are to be enhanced by sharing and reflecting the ideas.

According to Kurtovic, Vrdoljak, \& Idzanovic (2019) there are five features of accomplishment that could be incorporated into teachers' professional development programs are: (1) involving active learning instead of passive learning as an opportunity (2) rationality between theory and practice, (3) linking to the anxieties involving teachers, (4) capability to put on the facts and knowledge enlarged in schools at secondary school level in which the teachers are convoluted, and (5) teachers' mutual involvement in thoughtful practices which tends to approach indication which contribute to teachers' personal, social and emotional sustainability.

Teacher training programs at secondary school level urge to develop practical skills which aims to enhance ability to perform professionally and successfully while instructional strategies in the classroom Rubach et al. (2020). Key factors of instructional performance comprised of ability to teach in the classroom, predict a problem and solve it according to the prevailing situation at time. Such skills are related as action-oriented skills and can only be calculated authentically if the evaluation engrosses a valid depiction of a situation from real life (Seufert, Guggemos, $\&$ Sailer, 2020). Previously teachers used traditional methods like multiple-choice test, text-based questions, and teacher manifestations to measure related feature of teacher skill. To measure teacher's skill to respond to the prevailing situation requires a contextual nature and complexity of instructional environment which is only available in the real classroom. Empirical studies show that the performance of the teachers increased if they are trained with domain specific knowledge and response accordingly Saubern, Urbach, Koehler, \&Phillips (2020). It requires domain specific content, how to use that content while teaching in the classroom and how to apply that content to solve a problem. Performance of the teachers can also be enhanced by conceptualizing subject matter as content knowledge and teaching content knowledge which is required to teach students according to their cognition (Santagata \& Sandholtz, 2018). Teacher knowledge and application of teacher knowledge in practice 
can only be more relevant and if it is contextual in need based and facilitate the teaching- learning process.

Education and teacher training programs for in-service teachers endeavor to present maximum learning opportunity to both teacher knowledge and effective teacher performance in the classroom at secondary school level. In teacher training programs the development of teacher knowledge has evaluated domain specific and basic elements of teacher's knowledge and general educational knowledge for effective instructional practices that may be basic but not connected with the specific domain knowledge and affects the performance of the teacher in the classroom. Teachers' performance requires knowledge and skill to be used properly (Scherer \&Teo, 2019). The imparting of knowledge to the students in the classroom needs well organized and flexible sort of knowledge as well the attitude to deliver that knowledge. It needs professional training and content knowledge as well as subject knowledge to perform to get proper results.

Another factor involved in the professional development of the teachers for the effective performance is the use of the technology. Technology has burst the spread of knowledge. Now there is rush of knowledge. Information technology has given new dimensions to educational process (Rodriguez, Condom-Bosch, Ruiz, \& Oliver, 2020). It has facilitated the educational process and made it complex at the same time as well. Technology can be used in the teacher training programs to facilitate the teachers. As there are new devices which are being used to impart education throughout the world, the teachers must be aware of these techniques also. Many researches show that teachers' performance can be increased by using technology Farjon, Smits, \&Voogt, 2019. If modern in Pakistan must teach the students in the modern world, he/she must have to learn the use of new technology and get well equipped with modern gadgets to perform well in teaching learning process (Kaplon-Schilis \& Lyublinskaya, 2020). Yueh \& Chiang (2020) revealed that the technology used in the educational may be simple board or robot, its main aim is to facilitate the teacher to teach in the classroom. It is very important to understand the integrative role and relationship between the content or subject matter and the cognitive level of the students. Technology transforms and influences the teachers and the students at the same time. Performance is the outcome of what teachers transform to the students (Seufert, Guggemos, \&Sailer, 2020). Professional development of the in-service teachers is very important as it refreshes teachers' knowledge time to time to enhance new forms of knowledge. It provides an opportunity to the teachers to sustain whatever they have already been teaching and what has entered in that specific field. Change in knowledge id indispensable (Schmid, Brianza, and Petko,2020). It seems that some teachers understand the significance of the technology, but some teachers do not understand the need and gravity of the digital skills and still there are some teachers who think that 
they already have digital skills and do not need any further professional development. Attitude of the teacher also play a very important role in the professional development of the teacher especially for the in-service teachers as it is not easy to motivate the teacher to add to the existing knowledge. The in-service teachers are habitual with what sort of knowledge and the methods with which they are teaching becomes hard to change. Professional development aims to innovate the existing body of knowledge. It is teachers' belief which plays important role to adopt such attitude and get prepared to transform them (Farjon, Smits, \& Voogt, 2019). Attitude of the teachers also play a key role in adoption of technology in the instructional process. Will and skill of the inservice teachers has significant association and predictor of the adoption of educational innovations. Though, in the beginning it seems difficult, but the will and efficacy of the teacher and the motivation of the trainers can facilitate the teachers and encourage them to take active part in processional development programs (Kirschner \& Stoyanov, 2020).

\section{RESEARCH OBJECTIVE}

1. To determine the performance of secondary school teachers working in the public sector based on performance indicators

\section{RESEARCH QUESTION}

1. What are the strata wise performance levels of secondary school teachers on each indicator of instructional planning \& strategies?

\section{RESEARCH METHODOLOGY}

Quantitative research approach was used for ensuring larger generalizability. A cross sectional survey research design was applied to present a 'snapshot' of the outcomes and associated characteristics, at an explicit time.

\section{Population}

\section{Figure 1: Population of the study}

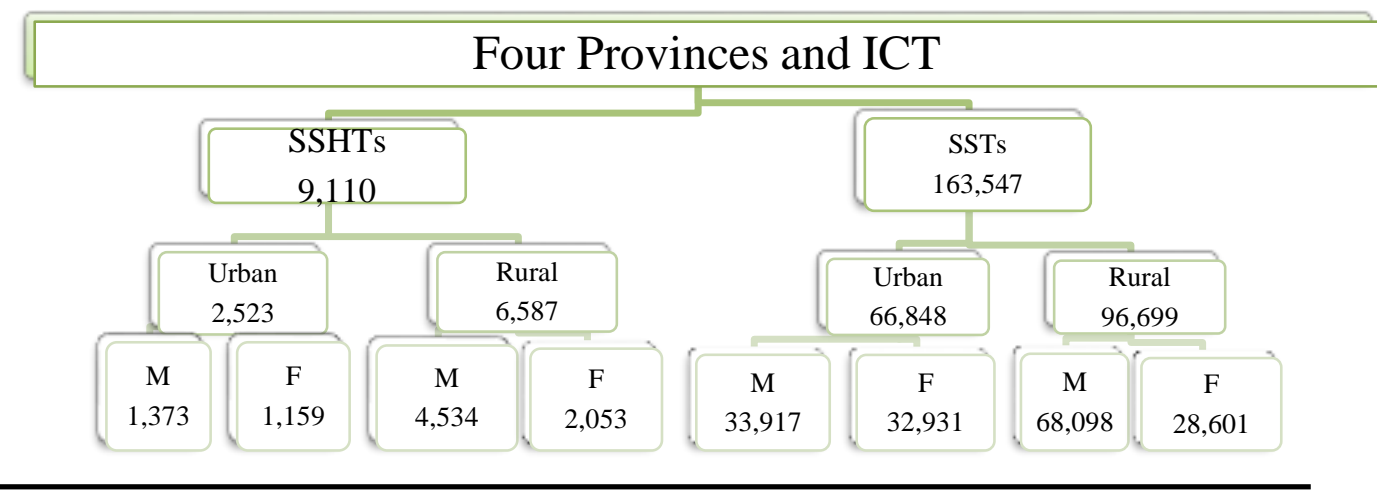




\section{Sampling}

According to multistage sampling a single district from every province was selected conveniently based on the political situation in the area and researchers' financial constraints. Moreover, one administrative unit (Tehsil) was randomly selected from each chosen district, along with Islamabad Capital Territory. Primarily 400 SSTs i.e., five teachers from each school were selected through proportionate stratified sampling technique. Further the head teacher at each school was included for the purpose of triangulation $400 \div 5=80$ head teachers were selected. Random sampling was done through draw card method.

Table 1: Strata wise distribution of the sample of the study

\begin{tabular}{llllllllllllll}
\hline $\begin{array}{l}\text { Sampl } \\
\text { e }\end{array}$ & $\begin{array}{l}\text { Cate } \\
\text { gory }\end{array}$ & ICT & & $\begin{array}{l}\text { Rawalpin } \\
\text { di }\end{array}$ & & $\begin{array}{l}\text { Central } \\
\text { Karachi }\end{array}$ & $\begin{array}{l}\text { Abbott } \\
\text { abad } \\
\text { Tehsil }\end{array}$ & $\begin{array}{l}\text { Zargh } \\
\text { oon } \\
\text { Town }\end{array}$ & $\begin{array}{l}\text { To } \\
\text { tal }\end{array}$ & $\begin{array}{l}\text { Sam } \\
\text { ple } \\
\text { Size }\end{array}$ \\
\hline & $\begin{array}{l}\text { Gen } \\
\text { der }\end{array}$ & M & F & M & F & M & F & M & F & M & F & & \\
SSHT & U & 1 & 1 & 5 & 5 & 4 & 3 & 1 & 1 & 2 & 1 & 1 & 80 \\
S & R & 1 & 1 & 20 & 11 & 5 & 2 & 9 & 4 & 2 & 1 & 1 & \\
SSTs & U & 5 & 5 & 25 & 25 & 20 & 15 & 5 & 5 & 10 & 5 & 5 & 400 \\
& $\mathrm{R}$ & 5 & 5 & 100 & 55 & 25 & 10 & 45 & 20 & 10 & 5 & 5 &
\end{tabular}

ICT: Islamabad Capital Territory

\section{Instrument of the Study}

Two rating scales were developed based on eight performance indicators for the collection of data, one from secondary school teachers and the other from secondary school head teachers regarding the performance of teachers working in their institutions at secondary school level.

\section{Validity and Reliability}

The items of the rating scales were validated by a group of experts. Their suggestions helped in the modification and finalization of the tools. The indicator wise reliability calculated after pilot testing is as under:

Table 2: Indicator wise Reliability of performance

\begin{tabular}{clcc}
\hline $\begin{array}{c}\text { S. } \\
\text { No }\end{array}$ & Performance Indicators & $\begin{array}{c}\text { No. of } \\
\text { items }\end{array}$ & A \\
\hline 1. & Designing suitable instruction & 3 & .81 \\
\hline
\end{tabular}




\begin{tabular}{llcc}
\hline 2. & Knowledge of culture in school, classroom \& & 2 & .76 \\
& community & 2 & .92 \\
3. & Evaluating teaching resources & 2 & .81 \\
4. & Strengthen learning through homework & 3 & .95 \\
5. & Creating learning experiences through strategies & 3 & .97 \\
6. & Organize instructional activities & 3 & .92 \\
7. & Methods of assessment formal \&informal & 2 & .93 \\
8. & Interdisciplinary experiences & 20 & .97 \\
Total & & & \\
\hline
\end{tabular}

The overall reliability of the tool was .97 which was acceptable for administration of the instrument on the sample for collection of required data.

\section{DATA ANALYSIS AND RESULTS}

Investigating the performance of public sector secondary school teachers based on performance indicators of instructional planning \& strategies as stated in the professional standards.

Table 3: Indicator wise performance of urban \& rural, male \& female secondary school teachers

\begin{tabular}{|c|c|c|c|c|c|c|c|c|c|c|c|c|c|c|}
\hline \multirow[t]{3}{*}{ Indicators } & \multicolumn{4}{|c|}{$\begin{array}{ll}\mathrm{M} & \mathrm{F} \\
\% & \% \\
\end{array}$} & \multicolumn{2}{|c|}{$\begin{array}{l}\mathrm{M} \\
\%\end{array}$} & \multicolumn{2}{|c|}{$\begin{array}{l}\mathrm{F} \\
\%\end{array}$} & \multicolumn{2}{|c|}{$\begin{array}{ll}\mathrm{M} & \mathrm{F} \\
\% & \%\end{array}$} & \multicolumn{2}{|c|}{$\begin{array}{ll}\mathrm{M} & \mathrm{F} \\
\% & \%\end{array}$} & \multicolumn{2}{|c|}{$\begin{array}{ll}\mathrm{M} & \mathrm{F} \\
\% & \%\end{array}$} \\
\hline & & $\begin{array}{c}\mathrm{R} \\
147\end{array}$ & $\mathrm{U}$ & $\begin{array}{l}\mathrm{R} \\
91\end{array}$ & $\begin{array}{l}\mathrm{U} \\
50\end{array}$ & $\begin{array}{r}\mathrm{R} \\
147\end{array}$ & $\mathrm{U}$ & & $\begin{array}{cc}\mathrm{U} & \mathrm{R} \\
50 & 147\end{array}$ & $\begin{array}{cc}\mathrm{U} & \mathrm{R} \\
57 & 91\end{array}$ & $\begin{array}{cc}\mathrm{U} & \mathrm{R} \\
50 & 147\end{array}$ & $\begin{array}{cc}\mathrm{U} & \mathrm{R} \\
57 & 91\end{array}$ & $\begin{array}{cc}\mathrm{U} & \mathrm{R} \\
50 & 147\end{array}$ & 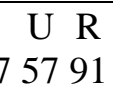 \\
\hline & & Po & & & & $\begin{array}{l}\text { Bel } \\
\text { aver }\end{array}$ & & & Aver & age & $\begin{array}{l}\text { Abov } \\
\text { avera }\end{array}$ & & $\begin{array}{l}\text { Requi } \\
\text { Stand }\end{array}$ & $\begin{array}{l}\text { iired } \\
\text { dard }\end{array}$ \\
\hline 1. & 2 & 2 & 1 & & 5 & 5 & 2 & & $18 \quad 25$ & 1320 & 4136 & 3438 & $34 \quad 32$ & 4036 \\
\hline 2. & 0 & 1 & 0 & 0 & 4 & 4 & 4 & 3 & 2124 & 1019 & $34 \quad 38$ & 3535 & $41 \quad 32$ & 5142 \\
\hline 3. & 1 & 0 & 3 & 0 & 6 & 6 & 4 & 6 & 2423 & 1422 & $36 \quad 43$ & 3031 & $33 \quad 28$ & 4841 \\
\hline 4. & 4 & 0 & 0 & 0 & 6 & 5 & 4 & 5 & $22 \quad 29$ & 2121 & 4141 & 3738 & $27 \quad 25$ & 3836 \\
\hline 5. & 1 & 0 & 1 & 0 & 4 & 2 & 1 & 4 & 1720 & 1016 & 3138 & 3029 & $48 \quad 39$ & 3358 \\
\hline 6. & 1 & 1 & 1 & 2 & 6 & 4 & 8 & 5 & $28 \quad 29$ & 3030 & $32 \quad 40$ & 3231 & $32 \quad 26$ & 3032 \\
\hline 7. & 1 & 1 & 1 & 3 & 8 & 6 & 6 & 5 & $25 \quad 27$ & 2930 & $39 \quad 42$ & 3841 & $27 \quad 24$ & 2621 \\
\hline 8. & 1 & 1 & 0 & 0 & 11 & 3 & 4 & 3 & 2130 & 1832 & 3347 & 4637 & $34 \quad 20$ & 3227 \\
\hline
\end{tabular}

Table 3 reveals the five levels of performance related to instructional planning \& strategies, where level 1 signifies poor, level 2 depicts below average, level 3 displays average, level 4 shows above average and level 5 reveals required standard. This 
required standard at level 5 is expected from the secondary school teachers as per the professional standards; for these standards signify the minimum benchmarks of performance.

While having a view of indicator 1 designing suitable instruction $75 \%$ of urban male teachers are in level four and five, where $41 \%$ are above average and $34 \%$ having the required standard. $74 \%$ of urban and rural female teachers, are at level four and five with urban having $34 \%$ above average and $40 \%$ at required standard whereas rural females are $38 \%$ above average and $36 \%$ at the required standard. Altogether $68 \%$ of rural male teachers fall in level four and five with a composition of $38 \%$ above average and $32 \%$ at required standard, respectively.

Related to indicator 2 which is about knowledge of culture in school, classroom \& community $86 \%$ of urban female teachers are at level four and five with $35 \%$ above average and $51 \%$ fulfilling the required standard. $77 \%$ rural female teachers are at level four and five with $35 \%$ and $42 \%$ at above average and required standard, respectively. Among male teachers $75 \%$ urban were at level four and five with $34 \%$ above average and $41 \%$ at the required standard. $70 \%$ rural male teachers fall in level four and five having $38 \%$ above average and $32 \%$ at required standard.

Pertaining to indicator 3 evaluation of teaching resources $78 \%$ urban female teachers fall in level four and five with $30 \%$ above average and $48 \%$ at required standard. $72 \%$ rural female teachers are in level four and five with $31 \%$ above average and $41 \%$ at required standard. $71 \%$ rural male teachers fall in level four and five where $43 \%$ are above average and $28 \%$ at required standard. $69 \%$ urban male teachers are placed in level four and five with $36 \%$ above average and $33 \%$ at required standard, respectively.

In view of indicator 4 strengthening learning through homework $75 \%$ of urban female teachers are at level four and five with $37 \%$ above average and $38 \%$ fulfilling the required standard. $74 \%$ rural female teachers are at level four and five with $38 \%$ and $36 \%$ at above average and required standard, respectively. Among male teachers $68 \%$ urban were at level four and five with $41 \%$ above average and $27 \%$ at the required standard.66\% rural male teachers fall in level four and five having $41 \%$ above average and $25 \%$ at required standard.

Overall, on indicator 5 creating learning experiences through strategies $87 \%$ rural female teachers are at level four and five with $29 \%$ above average and $58 \%$ at required standard. $79 \%$ urban male teachers are at level four and five with $31 \%$ and $48 \%$ at above average and required standard, respectively. $77 \%$ rural male teachers were at level four and five with 38\% above average and 39\% at the required standard. $66 \%$ 
urban female teachers fall in level four and five having 30\% above average and 33\% at required standard.

With reference to indicator 6 organizing instructional activities $66 \%$ rural male teachers fall in level four and five with $40 \%$ above average and $26 \%$ at required standard. 64\% urban male teachers are in level four and five with $32 \%$ each at above average and required standard. 63\% rural female teachers fall in level four and five where $31 \%$ are above average and $32 \%$ at required standard. $62 \%$ urban female teachers are placed in level four and five with $32 \%$ above average and $30 \%$ at required standard, respectively.

Based on indicator 7 methods of formal \&informal assessment $66 \%$ urban as well as rural male teachers are at level four and five with urban having the composition of $39 \%$ above average and $27 \%$ at required standard and rural $42 \%$ above average and $24 \%$ at required standard. Among the female teachers $64 \%$ urban teachers were at level four and five with $38 \%$ above average and $26 \%$ at the required standard and $62 \%$ rural teachers fall in level four and five having $41 \%$ above average and $21 \%$ at required standard.

Pinning to indicator 8 the use of interdisciplinary experiences $78 \%$ urban female teachers are placed in level four and five with $46 \%$ above average and $32 \%$ at required standard. $67 \%$ of both urban and rural male teachers are in level four and five with urban $33 \%$ above average and $34 \%$ at required standard and rural $47 \%$ above average and $20 \%$ at required standard. $64 \%$ rural female teachers are placed in level four and five with $37 \%$ above average and $27 \%$ at required standard, respectively.

Performance indicators wise holist view of level 5 the required standard reveals that $40 \%$ urban female, $36 \%$ rural female $34 \%$ urban male and $32 \%$ rural male secondary school teachers are able to design suitable instructions (Indicator 1); 51\% urban female, $42 \%$ rural female, $41 \%$ urban male and $32 \%$ rural male secondary school teachers know about the classroom, school and community culture(Indicator 2); 48\% urban female, $41 \%$ rural female, $33 \%$ urban male and $28 \%$ rural male secondary school teachers evaluate teaching materials (Indicator 3); 38\% urban female, 36\% rural female, $27 \%$ urban male and $25 \%$ rural male secondary school teachers are strengthening learning by planning homework (Indicator 4); 58\% rural female, 48\% urban male, $39 \%$ rural male and $33 \%$ urban female secondary school teachers use strategies to create learning experiences (Indicator 5); 32\% urban male, 32\% rural female, $30 \%$ urban female and $26 \%$ rural male secondary school teachers organize teaching learning activities (Indicator 6) ; 27\% urban male, 26\% urban female, 24\% rural male and $21 \%$ rural female secondary school teachers use formal and informal assessment (Indicator 7) and 34\% urban male, 32\% urban female and 27\% rural female 
and $20 \%$ rural male secondary school teachers apply interdisciplinary learning experiences (Indicator 8).

\section{Triangulation}

Data triangulation was carried to ensure the validity of the study.

Table 4: Triangulation of performance indicators

\begin{tabular}{|c|c|c|c|c|}
\hline & Performance Indicators & $\begin{array}{l}\% \text { Self- } \\
\text { report of } \\
\text { SSTs }\end{array}$ & $\begin{array}{l}\text { \%Reporting } \\
\text { by SSHTs }\end{array}$ & $\begin{array}{l}\text { Spearman's } \\
\text { Rho }\end{array}$ \\
\hline 1. & Designing suitable instruction & 36 & 33 & \\
\hline 2. & $\begin{array}{l}\text { Knowledge of culture in school, } \\
\text { classroom \& community }\end{array}$ & 39 & 28 & \\
\hline 3. & Evaluating teaching resources & 35 & 29 & \multirow{6}{*}{$\begin{array}{l}.858 \\
(.013)\end{array}$} \\
\hline 4. & $\begin{array}{l}\text { Strengthen learning through } \\
\text { homework }\end{array}$ & 30 & 23 & \\
\hline 5. & $\begin{array}{l}\text { Creating learning experiences } \\
\text { through strategies }\end{array}$ & 47 & 34 & \\
\hline 6. & Organize instructional activities & 29 & 27 & \\
\hline 7. & $\begin{array}{l}\text { Methods of assessment formal } \\
\text { \&informal }\end{array}$ & 24 & 20 & \\
\hline 8. & Interdisciplinary experiences & 26 & 20 & \\
\hline
\end{tabular}

Table 4 reflects the rating of performance of the secondary school teachers by their 80 secondary school head teachers and their self-reporting. Rank order correlation was calculated by applying Spearman's Rho, according to rank order correlation coefficient there was significant relationship between the reporting of head teachers of the teachers in their institution and the self-reporting of teachers. The reporting of the head teachers and self-reporting of the teachers showed convergence as the relationship between the ranks of both was strongly positive.

\section{CONCLUSIONS}

Based on the indicators wise findings it was concluded that both urban and rural female secondary school teachers were designing suitable instructions (Indicator 1), had knowledge of the classroom, school, and community culture (Indicator 2), were evaluating teaching materials (Indicator 3) and strengthening learning by planning homework (Indicator 4) more than their male counterparts. Whereas rural female teachers were using strategies to create learning experiences (Indicator 5) 
comparatively more than their fellow urban female or male teachers. Both urban male and rural female teachers were organizing teaching learning activities (Indicator 6) more than rural male or urban female teachers. Formal and informal assessment (Indicator 7) was used, and interdisciplinary learning experiences were applied (Indicator 8) relatively more by the urban male teachers as compared to other teachers.

\section{DISCUSSION}

The performance dimension had eight indicators for gauging the performance of secondary school teachers in instructional planning \& strategies. In this dimension, female secondary school teachers' performance was better than the male secondary school teachers because it is a common perception that female secondary school teachers are relatively more dedicated to the profession than the male secondary school teachers. The findings of the study are consistent with the results proposed by Nejati, Hassani and Sahrapour (2014) in which the female teachers proved to be better than the male teachers in instructional strategies. Whereas contradictory findings were reported in the same year by Shakir and Adeeb (2014) which concluded that the male secondary school teachers were more competent than the female secondary school teachers. The positive reporting of the secondary school teachers' performance by their head teachers indicates a cordial working environment in the secondary schools and moreover it displays a realistic self-reporting by the teachers.

Based on the findings, it was concluded that all the teachers urban, rural, male, and female needed capacity development at varying degree in all the indicators of performance to achieve the required level of instructional planning \& strategies as stated in the professional standard. Over all urban male secondary school teachers lacked expertise in strengthening learning by planning homework and use of formal and informal assessment; rural male secondary school teachers required capacity development in application of integrated learning experiences, use of formal and informal assessment, arranging teaching learning activities and strengthening learning by planning homework; urban and rural female secondary school teachers required maximum training in use of formal and informal assessment. Further, the favourable reporting of the performance of teachers by their heads indicated the satisfaction of the administration with the working of the faculty.

\section{RECOMMENDATIONS}

The professional development of the secondary school teachers in the performance dimension is prioritized according to their standard based performance on each indicator. The professional development of in-service secondary school teachers in the performance dimension may be according to the priority of what is lacking most in secondary school teachers and may proceed accordingly. 
The most prominent skill which needs to be developed is the use of formal and informal assessment (Indicator 7) and may be given the top priority in any professional development program then the focus may be on application of integrated learning experiences (Indicator 8), organizing teaching learning activities (Indicator 6) and evaluation of teaching resources (Indicator 3), strengthening learning by planning homework (Indicator 4 ), designing suitable instruction (Indicator 1), knowledge of the classroom, school, and community culture (Indicator 2), and creating learning experiences through strategies (Indicator 5) respectively. The components of professional development program should be of practical nature rather than theoretical as performance skills require action and due weight age may be assigned according to the developmental needs of the secondary school teachers who are the target audience.

\section{REFERENCES}

Amirali, M., Halai, A. (2010). Teachers' knowledge about the nature of mathematics: A survey of secondary school teachers in Karachi, Pakistan. Bulletin of Education and Research, 32(2), 45-61.

Boyd, D. J., Lankford, J. Loeb, S. Jonah E. Rockoff, \& James H. W. (2007). “The Narrowing Gap in New York City Teacher Qualifications and Its Implications for Student Achievement in High-Poverty Schools."Calder Working Paper 10. Washington, DC: The Urban Institute.

Brookfield, S. (2006). The skillful teacher: On technique, trust, and responsiveness in the classroom: Jossey-Bass Inc Pub.

Chatelier, S., and Rudolph, S. (2018). Teacher responsibility: shifting care from student to (professional) self? Br. J. Sociol. Educ. 39, 1-15. doi: 10.1080/ 01425692.2017 .1291328

Clotfelter, Charles T., Ladd, F. H., \&Vigdor, L. J. (2007). "How and Why Do Teacher Credentials Matter for Student Achievement?" Calder Working Paper 2. Washington, DC: The Urban Institute

Ehindero, O. J., \&Ajibade, Y.A. (2000). What our student says about how we teach. Ife J. Educ. Studies.7(1), 1-9.

Farjon, D., Smits, A., \&Voogt, J. M. (2019). Technology integration of pre-service teachers explained by attitudes and beliefs, competency, access, and experience. Computers \& Education, 130, 81-93. https://doi.org/10.1016/j.compedu.2018.11.010

Government of Pakistan. (2006). National Education Census (NEC-2005). Islamabad: Ministry of Education, Academy of Educational Planning and Management Statistics Division Federal Bureau of Statistics Islamabad.

Government of Pakistan. (2009). National Professional Standards for Teachers in Pakistan (NPST-2009). Islamabad: Ministry of Education.

Gutierrez-Cobo, M. J., Cabello, R., Rodiguez-Corrales, J., Megias-Robles, A., Gomez-Leal, R., and Fernandez-Berrocal, P. (2019). A comparison of the ability emotional intelligence of head teachers with schoolteachers in other positions. Front. Psychol. 10:841. doi: 10.3389/fpsyg.2019.00841 
Kaplon-Schilis, A., \& Lyublinskaya, I. (2020). Analysis of Relationship Between Five Domains of TPACK Framework: TK, PK, CK Math, CK Science, and TPACK of Preservice Special Education Teachers. Technology, Knowledge and Learning, 25(1), 2543. https://doi.org/10.1007/s10758-019-09404-X

Kirschner, P. A., \& Stoyanov, S. (2020). Educating youth for nonexistent/not yet existing professions. Educational Policy, 34(3), 477-517. https://doi.org/10.1177/0895904818802086

Kurtovic, A., Vrdoljak, G., and Idzanovic, A. (2019). Predicting procrastination: the role of academic achievement, self-efficacy, and perfectionism. Int. J. Educ. Psychol. 8, 1-26. doi: 10.17583/ijep.2019.2993

Kutaka, T. W., Smith, W. M., Albano, A. D., Edwards, C. P., Ren, L., and Beattie, H. L. (2017). Connecting teacher professional development and student mathematics achievement: a 4-year study of an elementary mathematics specialist program.J. Teach. Educ. 68, 140-154. doi: 10.1177/ 0022487116687551

Lampert, J., Ball, A., Garcia-Carrion, R., and Burnett, B. (2019). Poverty and schooling: three cases from Australia, the United States, and Spain. Asia Pac. J. Teach. Educ. 1-19. doi: 10.1080/1359866X.2019.1602863

Nejati, R., Hassani, T.M. \&Sahrapour, H.J. (2014). The Relationship between Gender and Student Engagement, Instructional Strategies, and Classroo m Management of Iranian EFL Teachers. Theory and Practice in Language Studies, Vol. 4 (6), 1219-1226

Petko, D. (2020). Quo vadis TPACK? Scouting the road ahead. EdMedia + Innovate Learning, 23, 1277-1286.

Rice, K. J. (2010). The Impact of Teacher Experience Examining the Evidence and Policy Implications.National Center for Analysis of Longitudinal Data in Educational Research.

Rodriguez, J. A., Condom-Bosch, J. L., Ruiz, L., \& Oliver, E. (2020). On the Shoulders of Giants: Benefits of Participating in a Dialogic Professional Development Program for InService Teachers. Frontiers in Psychology, 11. doi:10.3389/fpsyg.2020.00005

Santagata, R., \&Sandholtz, J. H. (2018). Preservice teachers' mathematics teaching competence:

Comparing performance on two measures. Journal of Teacher Education, 1-13. https://doi. org/10.1177/0022487117753575

Saubern, R., Urbach, D., Koehler, M., \& Phillips, M. (2020). Describing increasing proficiency in teachers' knowledge of the effective use of digital technology. Computers \& Education, 147, 103784.https://doi.org/10.1016/j.compedu.2019.103784

Scherer, R., \&Teo, T. (2019). Unpacking teachers' intentions to integrate technology: A metaanalysis. Educational Research Review, 27, 90-109. https://doi.org/10.1016/j.edurev.2019.03.001

Schmid, M., Brianza, E., \&Petko, D. (2020). Developing a short assessment instrument for Technological Pedagogical Content Knowledge (TPACK.xs) and comparing the factor structure of an integrative and a transformative model. Computers \& Education, 157, 103967. https://doi.org/10.1016/j.compedu.2020.103967

Seufert, S., Guggemos, J., \&Sailer, M. (2020). Technology-related knowledge, skills, and attitudes of pre- and in-service teachers: The current situation and emerging trends. Computers in Human Behavior, 106552. doi: 10.1016/j.chb.2020.106552 
Shakir, M., \&Adeeb, M. A. (2014). Performance Appraisal: An Evaluation of Teachers' Competencies Based on National Professional Standards in Pakistan. International Review of Social Sciences, 2 (12)

Sweller, J. (2020). Cognitive load theory and educational technology. Educational Technology Research and Development, 68(1), 1-16. https://doi.org/10.1007/s11423-019-09701-3

Yueh, H.-P., \& Chiang, F.-K. (2020). Editorial: AI and robotics in reshaping the dynamics of learning. British Journal of Educational Technology. Advance online publication. https://doi.org/10.1111/bjet.13017

YurtsevenAvci, Z., O'Dwyer, L. M., \& Lawson, J. (2020). Designing effective professional development for technology integration in schools. Journal of Computer Assisted Learning, 36(2), 160-177. https://doi.org/10.1111/jcal.12394 